\title{
RISK, UNCERTAINTY \& DECISIONS ABOUT AUSTRALIAN RETIREMENT VILLAGE RESIDENCY FOR SENIORS
}

\author{
Timothy Kyng, Ling Li, and Ayse Aysin Bilgin \\ Macquarie University, Australia \\ timothy.kyng@,mq.edu.au
}

\begin{abstract}
"Retirement Villages" (RVs) are a common form of housing for older people in Australia. RV contracts are very complex. RV residency terminates on death or ill health. At Macquarie we developed a free online RV financial calculator. This is designed to help consumers with understanding the contracts, comparison shopping, and avoiding costly mistakes. It takes account of longevity / health and financial risks. It converts the complex fee structure to a comparison rent payable monthly over the consumers expected healthy lifespan. RVs are much costlier than most consumers expect. The cost varies by gender and increases with age. This tool uses actuarial modelling utilising publicly available data on mortality and disability. The contracts have much in common with insurance policies. This is the first RV calculator available in Australia. The underlying actuarial model is very original and the calculator can handle the vast majority of contract designs.
\end{abstract}

